\title{
Human gastric alcohol dehydrogenase activity: effect of age, sex, and alcoholism
}

\author{
H K Seitz, G Egerer, U A Simanowski, R Waldherr, R Eckey, D P Agarwal, H W Goedde, \\ $\mathrm{J}-\mathrm{P}$ von Wartburg
}

\begin{abstract}
As various isoenzymes of gastric alcohol dehydrogenase exist and as the effect of sex and age on these enzymes is unknown, this study measured the activity of gastric alcohol dehydrogenase at high and low ethanol concentrations in endoscopic biopsy specimens from a total of 290 patients of various ages and from 10 patients with chronic alcoholism. Gastric alcohol dehydrogenase was also detected by immunohistological tests in biopsy specimens from 40 patients by the use of a polyclonal rabbit antibody against class I alcohol dehydrogenase. A significant correlation was found between the immunohistological reaction assessed by the intensity of the colour reaction in the biopsy specimen and the activity of alcohol dehydrogenase measured at $580 \mathrm{mM}$ ethanol. While alcohol dehydrogenase activity measured at $16 \mathrm{mM}$ ethanol was not significantly affected by age and sex, both factors influenced alcohol dehydrogenase activity measured at $580 \mathrm{mM}$ ethanol. Young women below 50 years of age had significantly lower alcohol dehydrogenase activities in the gastric corpus and antrum when compared with age matched controls (SEM) (6.4 (0.7) $v 8.8(0.6)$ $\mathrm{nmol} / \mathrm{min} / \mathrm{mg}$ protein; $\mathrm{p}<0.001$ and $6.0(1.3) v$ $9.5(1.3) \mathrm{nmol} / \mathrm{min} / \mathrm{mg}$ protein; $p<0.001)$. Over 50 years of age this sex difference was no longer detectable, as high $\mathrm{Km}$ gastric alcohol dehydrogenase activity decreases with age only in men and not in women. In addition, extremely low alcohol dehydrogenase activities have been found in gastric biopsy specimens from young male alcoholics $(2.2(0.5)$ $\mathrm{nmol} / \mathrm{min} / \mathrm{mg}$ protein), which returned to normal after two to three weeks of abstinence. The activity of alcohol dehydrogenase in the human stomach measured at $580 \mathrm{mM}$ ethanol is decreased in young women, in elderly men, and in the subject with alcoholism. This decrease in alcohol dehydrogenase activity may contribute to the reduced first pass metabolism of ethanol associated with raised ethanol blood concentrations seen in these people. (Gut 1993; 34: 1433-1437)
\end{abstract}

Recent studies in men ${ }^{1-3}$ and in rats ${ }^{45}$ have shown that a significant fraction of ingested ethanol fails to reach the blood and that it is not retained in the gastrointestinal tract but is metabolised by first pass metabolism. The enzyme responsible for ethanol oxidation in the human stomach is alcohol dehydrogenase. Pestalozzi et al $^{6}$ reported the presence of a low $\mathrm{K}_{\mathrm{m}}$ alcohol dehydrogenase in the human stomach by using immunohistology. Most recently, however, alcohol dehydrogenase isoenzymes with much lower affinity to ethanol have been detected in surgical specimens from the stomach ${ }^{78}$ and in gastric biopsy specimens. ${ }^{89}$ As it was reported that the activity of gastric alcohol dehydrogenase correlates with the first pass metabolism of ethanol, ${ }^{10}$ and as the first pass metabolism was decreased in women, ${ }^{10}$ in the alcoholic, ${ }^{2}$ and after cimetidine treatment ${ }^{11}$ leading to raised blood ethanol concentrations, ${ }^{210-12}$ we investigated the effect of sex, age, and chronic alcohol consumption on low and high $\mathrm{Km}$ alcohol dehydrogenase activity in biopsy specimens from the corpus and antrum of the stomach.

\section{Methods}

PATIENTS

A total of 290 patients had gastroscopies and biopsy specimens (wet weight: $3-12 \mathrm{mg}$ ) were taken from apparently normal areas of the gastric corpus, or antrum, or both. Of the 290 patients, 118 were men and 172 were women with an age between 18 and 83 years. All patients required gastroscopy because of medical indications including dyspeptic symptoms and tumour exclusion. None of the patients were receiving $\mathrm{H}_{2}$ receptor antagonist treatment. Patients with Helicobacter pylori infection and with moderate or severe gastritis determined by light microscopy were excluded from the study. The gastroscopy was carried out with an Olympus GIF $Q$ endoscope and the biopsy specimen was taken by a forceps type FB3K. The study was approved by the ethics committee of the Department of Medicine, University of Heidelberg, Germany. The patients did not have any history of chronic alcohol abuse. In addition, biopsy specimens were taken from nine male alcoholics (age: 30-75 years) and from one female alcoholic (age: 45 years) at the time of hospital admission. All of these patients reported an intake of more than $100 \mathrm{~g}$ ethanol per day and all of them had raised serum $\gamma$-glutanyltransferase activities. In addition, all patients had histologically moderate to severe gastritis. Three of these patients had another biopsy during their stay in hospital after 14 and 19 days of abstinence from ethanol. At this time, gastric morphology returned to normal.

DETERMINATION OF ALCOHOL DEHYDROGENASE IN GASTRIC BIOPSY SPECIMENS

The biopsy specimens were frozen immediately and kept at $-80^{\circ} \mathrm{C}$ until used. The tissue was homogenised in $100 \mathrm{mM}$ glycine buffer, $\mathrm{pH} \mathrm{9.6}$ using a specially designed homogeniser for 
Eppendorf vials and finally centrifuged at $27000 \mathrm{~g}$ for 15 minutes. The supernatant was used to determine alcohol dehydrogenase activity at $22^{\circ} \mathrm{C}$ in $100 \mathrm{mM}$ glycine buffer, $\mathrm{pH} \mathrm{9.6}$ with a final ethanol concentration of either $16 \mathrm{mM}$ or $580 \mathrm{mM}$, and a nicotine adenine dinucleotide concentration of $2.6 \mathrm{mM}$. The human stomach contains three isoenzymes of alcohol dehydrogenase: The $\gamma$-alcohol dehydrogenase forms (class I) with a $\mathrm{K}_{\mathrm{m}}$ of $1-2 \mathrm{mM}$ at $\mathrm{pH} 10 \cdot 0$, the $\sigma$-alcohol dehydrogenase (class IV) with a $\mathrm{K}_{\mathrm{m}}$ of $11 \mathrm{mM}$ at $\mathrm{pH} 10 \cdot 0$, and $\chi$-alcohol dehydrogenase (class III), which cannot be saturated with ethanol. At $16 \mathrm{mM}$ ethanol $\gamma$-alcohol dehydrogenase isoenzymes are saturated, $\sigma$-alcohol dehydrogenase is partially saturated, and $\chi$-alcohol dehydrogenase is not active. At $580 \mathrm{mM}$ ethanol $\gamma$-alcohol dehydrogenase is partially inhibited by excess of substrate, $\sigma$-alcohol dehydrogenase is saturated, and $\chi$-alcohol dehydrogenase has also a small contribution to the activity measured. The complexity of the system makes it impossible to differentiate clearly between the activities corresponding to each enzyme. Therefore, in this paper alcohol dehydrogenase activities measured at $16 \mathrm{mM}$ and 580 $\mathrm{mM}$ ethanol are referred to activities of alcohol dehydrogenase with low or high ethanol concentrations.

The soluble protein content in the supernatant fraction was measured according to the method of Lowry $e t a l^{13}$ using bovine serum albumin as as standard.

\section{IMMUNOHISTOLOGY OF GASTRIC ALCOHOL DEHYDROGENASE}

Chemicals - protein A and sepharose CL-4B were obtained from Pharmacia Inc (Uppsala, Sweden), and horseradish peroxidase from Sigma Chemical Co (St Louis, Mo). Protein A-peroxidase was prepared as described. ${ }^{14}$

Immunochemicals - pyrazole sensitive human liver alcohol dehydrogenase was purified and characterised as described and used to elicit antibodies in rabbits. ${ }^{15}$ Anti-alcohol dehydrogenase antibodies were purified by affinity chromatography: human liver alcohol dehydrogenase was immobilised on $\mathrm{CNBr}$-activated sepharose CL-4B according to the method described previously.$^{16} \mathrm{~A}$ mixture of $10 \mathrm{ml}$ antiserum and $10 \mathrm{ml}$ of alcohol dehydrogenase-sepharose was incubated at $4^{\circ} \mathrm{C}$ overnight. The suspension was poured into a $0.9 \mathrm{~cm}$ diameter chromatography column. The gel was washed with $0.05 \mathrm{M}$ phosphate buffered saline, $\mathrm{pH} 7 \cdot 4$, followed by 2 $M$ sodium chloride in phosphate buffer. ${ }^{17}$ Antibodies bound in the column were eluted with $3 \mathrm{M}$ thiocyanate, $\mathrm{pH} 6$, immediately dialysed against phosphate buffered saline $(3 \times 2 \times 1)$, and concentrated in an Amicon ultrafiltration gel (Amicon Coop, Danvers, Mass) with PM-10 membrane to a protein concentration of $3-4 \mathrm{mg} / \mathrm{ml}$. All elutions were carried out at a flow rate of $80 \mathrm{ml} / \mathrm{h}$. The breakthrough fraction of the affinity chromatography column - that is, antiserum depleted of specific anti-alcohol dehydrogenase antibodies, was concentrated to the original volume and used as negative control (immunoadsorbed antiserum).
Tissue section - gastric biopsy specimens were immediately fixed in $4 \%$ phosphate buffered formaldehyde, $\mathrm{pH} 7 \cdot 4$, embedded in paraplast, sectioned at a thickness of 5 micron and mounted on microscopic slides. Three to five sections of each specimen were tested for the alcohol dehydrogenase content with the following immunohistochemical staining method: alcohol dehydrogenase was localised with anti-alcohol dehydrogenase antibodies. Bound antibodies were detected with a protein-A-peroxidase conjugate. The intensity of the staining was graded independently by a pathologist.

\section{STATISTICAL ANALYSIS}

Results were expressed as mean (SEM). The statistical significance of the differences in alcohol dehydrogenase activity were assessed by the Student's unpaired $t$ test. p Values under 0.05 were considered to show statistical significance. The correlation between alcohol dehydrogenase activity and the intensity of the immunoreaction was analysed by the Spearman non-parametric method.

\section{Results}

In biopsy specimens from the human stomach alcohol dehydrogenase can be detected immunohistochemically in parietal and mucus producing cells and to a lesser degree in chief cells. The intensity, however, of the immunoreaction illustrated as pigment development varies interindividually (Fig 1). A significantly positive correlation was found between the intensity of the immunoreaction and the alcohol dehydrogenase activity measured with $580 \mathrm{mM}$ ethanol by using the same biopsy specimen divided into two parts to perform both determinations (Fig 2).

When alcohol dehydrogenase activity was measured in gastric biopsy specimens at an ethanol concentration of $580 \mathrm{mM}$ no significant differences in the enzyme activity were found between the corpus and the antrum of the stomach (Table). Younger women, however, had a significantly lower alcohol dehydrogenase activity compared with age matched men, and elderly men showed a significantly lower alcohol dehydrogenase activity compared with younger men (Table). Figure 3 shows the effect of both age and sex on the activity of gastric alcohol

Effect of age and sex on gastric alcohol dehydrogenase activity

\begin{tabular}{|c|c|c|c|}
\hline & $\begin{array}{l}\text { Age } 17-50 \text { years } \\
(\mathrm{mmol} / \mathrm{mg} \\
\text { protein } / \mathrm{min})\end{array}$ & $p$ Values & $\begin{array}{l}\text { Age } 50-85 \text { years } \\
(\text { nmol/mg } \\
\text { protein/min })\end{array}$ \\
\hline $\begin{array}{c}\text { Women } \\
\text { Antrum } \\
\text { Men }\end{array}$ & $\begin{array}{l}6 \cdot 0(1 \cdot 3) \neq(\mathrm{n}=9) \\
\mathrm{p}<0 \cdot 001 \\
9 \cdot 5(1 \cdot 3)(\mathrm{n}=11)\end{array}$ & $\begin{array}{l}\text { NS } \\
p<0.001\end{array}$ & $\begin{array}{l}7 \cdot 1(0.6) \ddagger(n=14) \\
\mathrm{p}<0 \cdot 001 \\
3 \cdot 7(0.4)(\mathrm{n}=9)\end{array}$ \\
\hline $\begin{array}{l}\text { Women } \\
\text { Corpus }{ }^{\star} \\
\text { Men }\end{array}$ & $\begin{array}{l}6.4(0.7) \ddagger(n=14) \\
p<0.001 \\
8.8(0.6)(n=15)\end{array}$ & $\begin{array}{l}\text { NS } \\
p<0.001\end{array}$ & $\begin{array}{l}6 \cdot 2(0 \cdot 7)(n=19) \\
p<0 \cdot 001 \\
4 \cdot 7(0 \cdot 6)(n=14)\end{array}$ \\
\hline $\begin{array}{l}\text { Women } \\
\text { Corpust } \\
\text { Men }\end{array}$ & $\begin{array}{l}5 \cdot 4(0 \cdot 8)(n=20) \\
\text { NS } \\
6 \cdot 7(1 \cdot 3)(n=12)\end{array}$ & $\begin{array}{l}\text { NS } \\
\text { NS }\end{array}$ & $\begin{array}{l}6 \cdot 7(0 \cdot 8)(n=26) \\
N S \\
5 \cdot 2(0 \cdot 8)(n=18)\end{array}$ \\
\hline
\end{tabular}

*Alcohol dehydrogenase activity measured at $580 \mathrm{mM}$ ethanol; †Alcohol dehydrogenase activity measures at $16 \mathrm{mM}$ ethanol; $\dagger$
$\ddagger 0.001$ for the comparison with men in the same group; results expressed as mean (SEM). 
Figure 1: Immunohistology of gastric alcohol dehydrogenase using a polyclonal rabbit antibody against human hepatic alcohol dehydrogenase and the PAP method. Different degrees of immunoreactivity of gastric alcohol dehydrogenase in human seen: no alcohol

dehydrogenase activity detactable (upper left), minimal immunoreaction (upper right), moderate immunoreaction (lower left corner), strong immunoreaction (lower right). Haematoxylin counterstain, original magnification $\times 100$ ). gastric biopsy specimens are

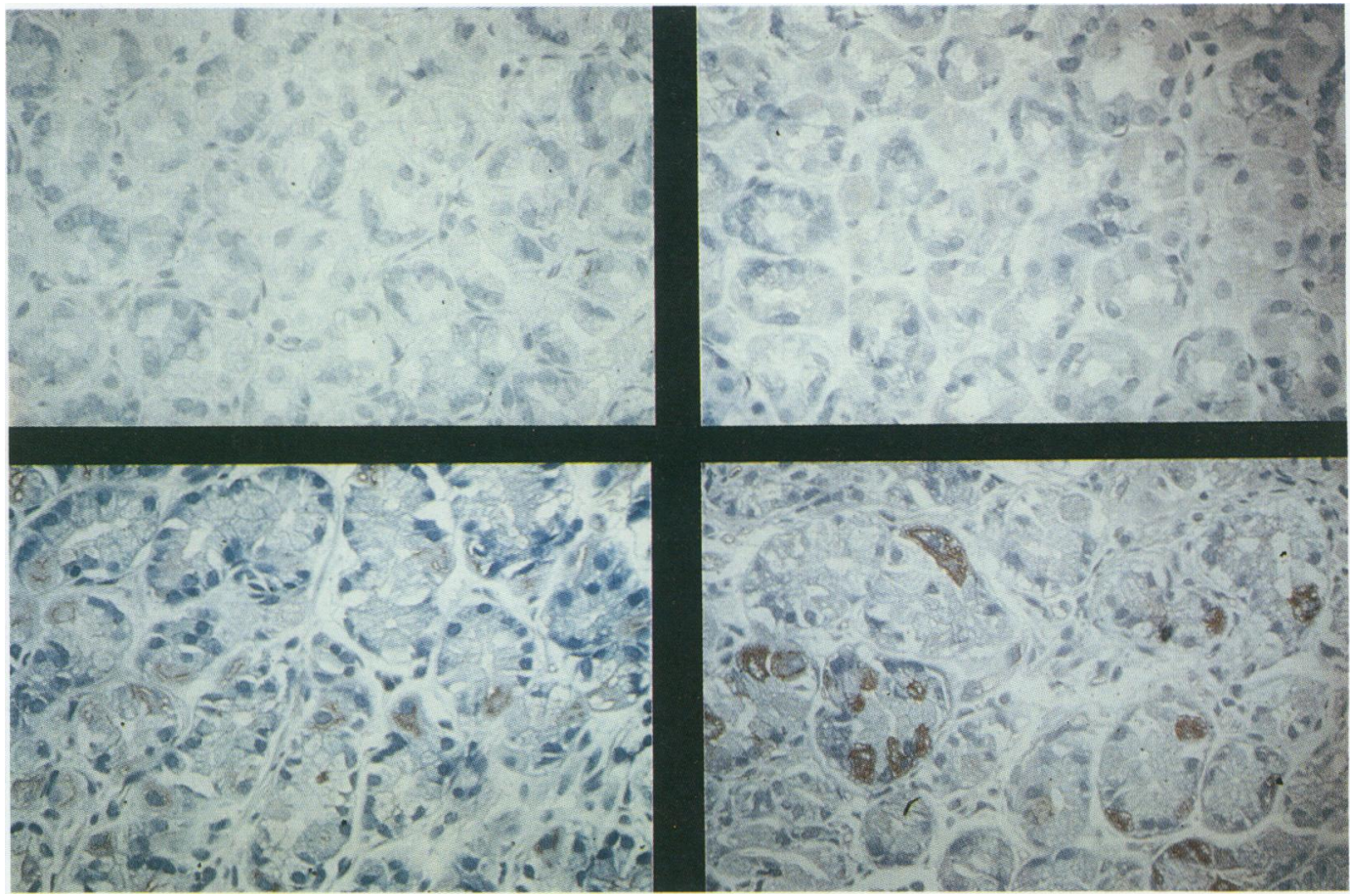

dehydrogenase measured at $580 \mathrm{mM}$ ethanol. While the activity of the enzyme stays fairly constant during the life time in women, a sharp decrease of the activity is seen in men between the age of 40 to 50 years. This is in contrast with the alcohol dehydrogenase activity measured at $16 \mathrm{mM}$ ethanol (Table). Neither age nor sex had a significant effect on this enzyme activity, although a trend towards lower activities in younger women and in elderly men can also be detected. Finally, alcoholics had a strikingly low gastric alcohol dehydrogenase activity at 580 $\mathrm{mM}$ ethanol compared with non-alcoholics (Fig 4). The 45 year old woman with chronic alcoholism had a gastric alcohol dehydrogenase activity of $0.7 \mathrm{nmol} / \mathrm{mg}$ protein $/ \mathrm{min}$. Three of the nine male alcoholics could be biopsied again during hospital stay 14 to 19 days after abstinence

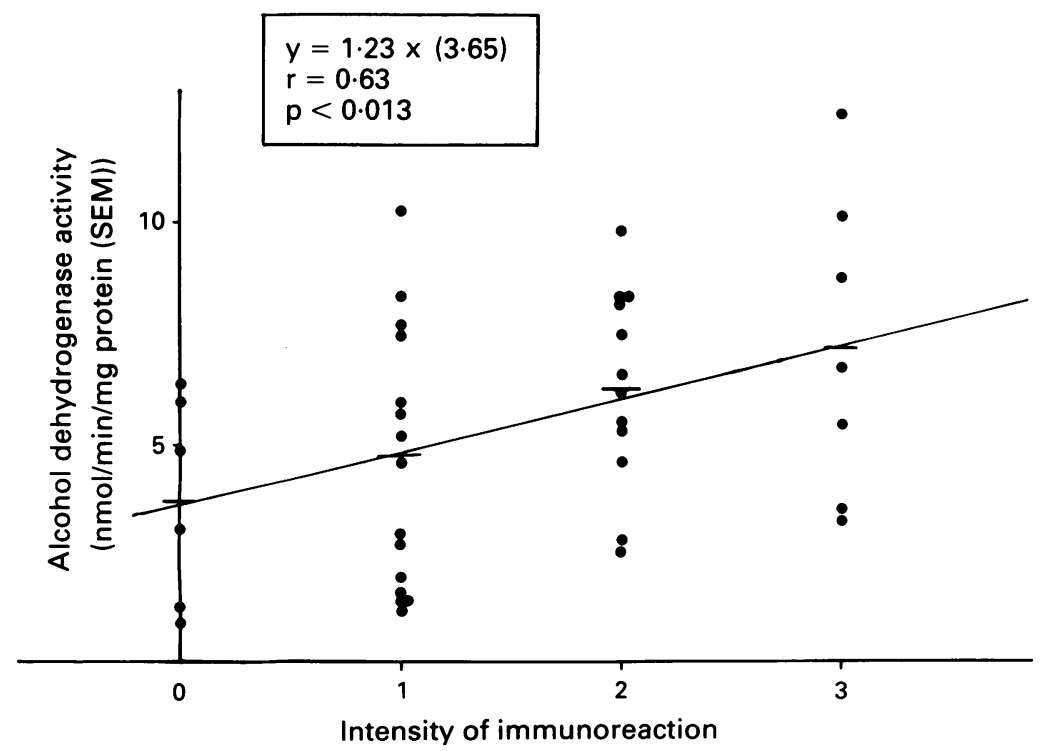

Figure 2: Correlation between immunoreactivity (expressed as no $=0$, minimal $=1$, moderate $=2$, and strong $=3$ immunoreactivity) of gastric alcohol dehydrogenase and the enzyme activity measured in the same gastric biopsy specimens at $580 \mathrm{mM}$ ethanol. from alcohol. All three showed a complete return to normal of the enzyme activity.

\section{Discussion}

The data presented show the presence of at least two types of alcohol dehydrogenase isoenzymes in endoscopic biopsy specimens from the human stomach with different activities. One isoenzyme has a low $\mathrm{K}_{\mathrm{m}}$ for ethanol comparable with that of class I alcohol dehydrogenase isoenzymes as defined for the liver. ${ }^{18}$ This enzyme has already been described in necropsy, ${ }^{19}$ and in fresh surgical specimens. ${ }^{720}$ By using fresh gastric mucosa, Hernandez-Munoz et $\mathrm{al}^{7}$ found that this low $\mathrm{K}_{\mathrm{m}}$ enzyme has an optimal $\mathrm{pH}$ of $10 \cdot 6$, is very sensitive to the inhibition by 4-methylpyrazole, and migrates cathodically on electrophoresis. This enzyme could also be detected here by immunohistology using a polyclonal rabbit antibody against human liver class I alcohol dehydrogenase. The other type of alcohol dehydrogenase has a much lower affinity to ethanol but with activities that become significant at ethanol concentrations commonly present in the human stomach after alcohol consumption..$^{21}$ It has been shown that one high $\mathrm{K}_{\mathrm{m}}$ isoenzyme has a $\mathrm{pH}$ optimum of $10 \cdot 5$, is refractory to the inhibition by 4-methylpyrazole, and has kinetic properties corresponding to the class III '(or $\chi$-alcohol dehydrogenase) isoenzyme. ${ }^{722}$ In addition, a new alcohol dehydrogenase isoenzyme, named $\sigma$-alcohol dehydrogenase has been purified from the human stomach. ${ }^{9}$ This enzyme is a class IV isoenzyme but differs from $\pi$-alcohol dehydrogenase, has a $\mathrm{pH}$ optimum of $\mathbf{9 \cdot 9}$, and a $\mathrm{K}_{\mathrm{m}}$ of $41 \mathrm{mM}$ at $\mathrm{pH} \mathrm{7 \cdot 4} .^{9}$ This gastric isoenzyme has also been detected in the rat $^{23}$ and in the baboon ${ }^{24}$ and therefore its occurrence may be widespread in mammals. Thus, three different types of alcohol dehydrogenase isoenzymes are capable of oxidising ethanol in the mucosa of the human stomach. To measure the overall metabolism of 


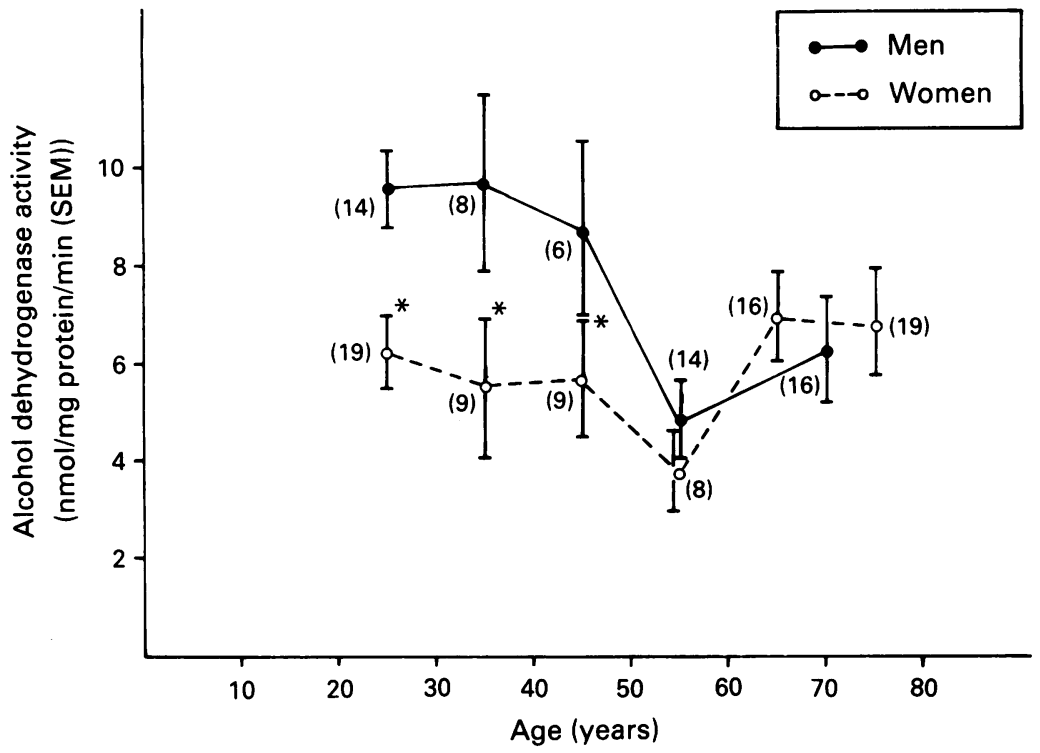

Figure 3: Effect of age and sex on the activity of human gastric alcohol dehydrogenase measured at $580 \mathrm{mM}$ ethanol. ${ }^{\star}$ Significantly lower $(p<0.01)$ compared with age matched men. weight of the total gastric mucosa in humans is not known. Gastric alcohol dehydrogenase may be responsible for the local production of acetaldehyde, even after a comparitively low oral intake of ethanol, and considering the toxicity of acetaldehyde, it could contribute to mucosal injury commonly seen after alcohol consumption. ${ }^{25}$

Various conditions have been reported under which ethanol blood concentrations increase after oral intake of ethanol including fasting, ${ }^{2}$ chronic alcoholism, ${ }^{2}$ cimetidine treatment, ${ }^{11-13}$ and in women. ${ }^{10}$ It has been suggested that the increased availability of ethanol is due to decreased first pass metabolism of alcohol in the stomach. Furthermore, as it was found that the first pass metabolism of ethanol (which is the difference between the ethanol blood concentration time curve obtained after intravenous and oral application of alcohol) correlates significantly with the activity of gastric alcohol dehydrogenase measured in endoscopic biopsy specimens, it was concluded that the increased availability of ethanol in women is due to a decreased gastric alcohol dehydrogenase activity. The data presented here confirmed the results of Frezza et $a l^{10}$ and earlier results from our laboratory ${ }^{26}$ that women exhibit a significantly lower gastric alcohol dehydrogenase activity than men when alcohol dehydrogenase is measured at high ethanol concentrations. This effect of sex, however, on gastric alcohol dehydrogenase activity is age dependent. While the activity of gastric alcohol dehydrogenase in man drops significantly during the fourth and fifth decade and becomes similar to that of women, the activity in women stays more or less constant at a lower activity level for the life time. A similar age effect as for gastric alcohol dehydrogenase has been seen for hepatic alcohol dehydrogenase..$^{27}$ Although a sex specificity of hepatic alcohol dehydrogenase distribution profile in younger age groups has been reported, this sex difference was no longer apparent after the age of 50 years. ${ }^{27}$ It is of interest to note that neither female sex nor advanced age exhibit a significant suppressive effect on gastric alcohol dehydrogenase activity measured at low ethanol concentrations.

We have recently reported raised blood ethanol concentrations in parents after an oral intake of $0.3 \mathrm{~g}$ per $\mathrm{kg}$ body weight of ethanol compared with their children. ${ }^{26}$ These raised ethanol blood concentrations have been attributed to a decreased distribution volume for ethanol with advanced age. ${ }^{28}$ On the basis of the results presented here raised ethanol blood concentrations after oral alcohol administration in the elderly could be due, at least in part, to a decreased gastric first pass metabolism of alcohol by alcohol dehydrogenase.

Moreover, gastric alcohol dehydrogenase activity has been found to be extremely low in chronic alcoholics. The alcohol dehydrogenase activity was only $10-20 \%$ of that seen in sex and age matched controls. Therefore, as a result of this decreased alcohol dehydrogenase activity, first pass metabolism can be strikingly decreased in these individuals leading to raised ethanol blood concentrations as reported before. ${ }^{2}$ It is of
Figure 4: Effect of chronic ethanol consumption on the activity of human gastric alcohol dehydrogenase measured at $580 \mathrm{mM}$ ethanol in biopsy specimens from the corpus of male patients above and below 50 years of age. The data for nonalcoholics are those used in the table. ${ }^{\star}$ Significantly lowe $(p<0.001)$ compared with patients below 50 years of age $\star \star$ Significantly lower $(p<0.001)$ compared with patients above 50 years of age. 
interest that the gastric alcohol dehydrogenase activity in alcoholics can return to normal values during abstinence, which may be explained by a normalisation of the gastric mucosa during alcohol withdrawal.

In conclusion, the decrease of gastric alcohol dehydrogenase activity seen in women and in elderly men together with a smaller volume of distribution of ethanol in these populations may result in raised ethanol blood concentrations. Such a rise of ethanol blood concentrations may be further enhanced by chronic alcohol abuse, by fasting, or with cimetidine treatment. This should be considered in the definition of safe levels of drinking for men and women of various ages driving motor vehicles or engaging in other activities requiring a high degree of attention or co-ordination.

This work was supported by an ASCHE Forschungsstipendium to HKS and by the Deutsche Forschungsgemeinschaft.

Part of this study was presented in abstract form at the Annual Meeting of the American Gastroenterological Association 1990 (Gastroenterology 1990; 98: A629).

1 Julkunen RJK, DiPadova C, Lieber CS. First pass metabolism of ethanol - a gastrointestinal barrier against the systemic toxicity of ethanol. Life Sci 1985; 37: 567-73.

2 DiPadova C, Worner TM, Julkunen RJK, Lieber CS. Effects of fasting and chronic ethanol consumption on the first pass of fasting and chronic ethanol consumption on the first pass

3 Caballeria J, Frezza M, Hernandez-Munoz R, DiPadova C, Korsten A, Baraona E, et al. The gastric origin of the first pass metabolism of ethanol in man: effects of gastrectomy. Gastroenterology 1989; 97: 1205-9.

4 Julkenen RJK, Tannenbaum L, Baraona E, Lieber CS. First pass metabolism of ethanol: an important determinant of 437-41.

5 Caballeria J, Baraona E, Lieber CS. The contribution of the stomach to ethanol oxidation in the rat. Life Sci 1987; 41: 1021-7.

6 Pestalozzi DM, Bühler R, von Wartburg JP, Hess $M$ Immunohistochemical localization of alcohol dehydrogenase inmunohistochemical localization of alcohol dehydrogenase in the human $1011-6$.

7 Hernandez-Munoz R, Caballeria J, Baraona E, Uppal R, Greenstein R, Lieber CS. Human gastric alcohol dehydrogenase: its inhibition by $\mathrm{H} 2$-receptor antagonists, and its effect on the availability of ethanol. Alcohol Clin Exp Res 1990; 14: $946-50$

8 Seitz HK, Egerer G, Oertel U, Xu Y, Simanowski UA, Wermuth B, v Wartburg JP. Biochemical and immunohistological studies on alcohol dehydrogenase in the human stomach: effect of age, sex, alcoholism and cimetidine. Gastroentrology 1990; 98: A629.
9 Moreno A, Pares X. Purification and characterization of a new alcohol dehydrogenase from human stomach. $7 \mathrm{Biol}$ Chem 1991; 266: 1128-33.

10 Frezza M, DiPadova C, Pozzato G, Terpin M, Baraona E Lieber CS. High blood alcohol levels in women: the role of decreased gastric alcohol dehydrogenase activity and first pass metabolism. NEngl F Med 1990; 322: 95-9.

11 Caballeria J, Baraona E, Rodamilans M, Lieber CS. Effects of cimetidine on gastric alcohol dehydrogenase activity and blood levels of ethanol. Gastroenterology 1989; 96: 388-92.

12 Seitz HK, Veith S, Czygan P, Boesche J, Simon B, Gugler R, et $a l$. In vivo interaction between $\mathrm{H}_{2}$-receptor antagonists and ethanol metabolism in man and in rats. Hepatology $1984 ; 4$ : 1231-4.

13 Lowry OH, Rosenbrough NJ, Farr AL, Randall RJ. Protein measurement with the folin phenol reagent. $\mathcal{F}$ Biol Chem 1951; 193: 265-75.

14 Nakane PK, Kawaoi A. Peroxidase labelled antibody, a new method of conjugation. 7 Histochem Cytochem 1974; 22: 1084-91.

15 Buehler R, Hess M, v Wartburg JP. Immunohistochemical localization of alcohol dehydrogenase in liver tissue, cultured fibroblast and HeLa cells. Am $\mathcal{F}$ Pathol 1982; 108: 89-99.

16 Cuatrecasas P, Anfinsen CB. Affinity chromatography. In: Colowick SP, Kaplan NO, eds. Methods in enzymology. New York: Academic Press, 1971: 345.

17 Zoller M, Matzuki S. Antigen and antibody purification by immunoabsorption: elimination of non-biospecifically bound proteins. F Immunol Methods 1976; 11: 287-95.

18 Vallee BL, Bazzone TI. Isoenzymes of human liver alcohol dehydrogenase. In: Ratazzi M, Scandalios JG, Whitt GS, dehydrogenase. In: Ratazzi M, Scandalios $\mathrm{JG}$, Whitt GS, eds. Isoenzymes. Current topics in biological and medic
research. Vol 8. New York: Alan R Liss, 1983: 219-44.

19 Hempel JD, Pietruszko R. Human stomach alcohol dehydrogenase: isoenzyme composition and catalytic properties. Alcohol Clin ExpRes 1979; 3; 95-8.

20 Seitz HK, Simanowski UA, Egerer G, Waldherr R, Örtl U. Human gastric Alcoholdehydrogenase: In vitro characteristics and effect of cimetidine. Digestion 1992; 51: 80-5.

21 Halsted CH, Robles EA, Mezey E. Distribution of ethanol in the human gastrointestinal tract. Am $\mathcal{F}$ Clin Nutr 1973; 26: $831-4$.

22 Wagner FW, Pares X, Holmquist B, Vallee BL. Physical and

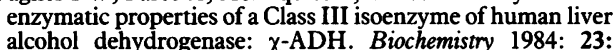
2193-9.

23 Julia P, Farres J, Pares X. Characterization of three isoenzymes of rat alcohol dehydrogenase: tissue distribution and physical and enzymatic properties. Eurf Biochem 1987; 162: 179-89.

24 Holmes RS, Courtny YR, Vandeberg JL. Alcohol dehydrogenase isoenzymes in baboons: tissue distribution, catalytic properties, and variant phenotypes in liver, kidney, stomach and testis. Alcohol Clin Exp Res 1986; 10: 623-30.

25 Gottfried EB, Korsten MA, Lieber CS. Alcohol induced gastric and duodenal lesions in man. Am $\mathcal{f}$ Gastroenterol 1978; 70: 587-92.

26 Egerer G, Simanowski UA, Schmier M, Chang G, Bogusz M, Seitz HK. Effect of age on the first pass metabolism of ethanol in man. In: Kuriyama $\mathrm{K}$, Takada $\mathrm{A}$, Ishii $\mathrm{H}$, eds. Biochemical and social aspects of alcohol and alcoholism (ISBRA), Kyoto, Fapan. Amsterdam: Excerpta Medica, 1988: 115-8.

27 Maly IP, Sasse D. Intraacinar profiles of alcohol dehydrogenase and aldehyde dehydrogenase activities in human liver. Gastroenterology 1991; 101: 1716-23.

28 Vestal RE, McGuire EA, Tobin JD, Andres R, Norris AH, Mezey E. Aging and ethanol metabolism. Clin Pharmacol Ther 1977; 21: 343-54. 